\title{
Determination of sharing oil losses using proportional and stratified methods in Krisna field
}

\author{
Yulius Deddy Hermawan ${ }^{1}$ (D) Dedy $\mathrm{Kristanto}^{2} \cdot$ Hariyadi $^{2} \cdot$ Wibowo $^{2}$
}

Received: 28 October 2018 / Accepted: 25 June 2019 / Published online: 1 July 2019

(c) The Author(s) 2019

\begin{abstract}
This paper discusses about the oil losses due to emulsion, flash, and mixing oil phenomena that frequently happened in the oil and gas companies. The goals of this work are to calculate the emulsion and vapor correction volumes, shrinkage correction volume of the mixture of two or more crude oils with different densities, and to compare between the common proportional method that usually utilized in petroleum industries and the new proposed stratified method for determining of sharing oil losses. The mixing of crude oils from 7 shippers in Krisna field would be used as a case study, and the equation of API 12.3 was chosen to calculate a shrinkage correction volume. Oils from shippers S1, S2, and S3 were first mixed together in TANK-1 of the 1st station; the mixed oil of TANK-1 was then transported to the next station and stored in the TANK-2 and mixed with other oils from shippers S4 and S5; and finally, the mixed oil of TANK-2 was transported to the final station and stored in the TANK-3 and mixed with other oils from shippers S6 and S7. The proportional method gave almost the same shrinkage correction factor (SCF) for all shippers about $0.20 \%$, while stratified method resulted SCF in between 0.05 and $0.31 \%$. Based on our analysis, more often oil mixes with others its volume would be more decreased. The stratified method is therefore recommended to determine sharing oil losses since it gives a fair result.
\end{abstract}

Keywords Emulsion $\cdot$ Flash $\cdot$ Oil losses $\cdot$ Mixing oil $\cdot$ Proportional $\cdot$ Shrinkage $\cdot$ Stratified

\section{Introduction}

Sources of oil loss in petroleum industries are emulsion, evaporative (flash), shrinkage, leakage, theft, and measurement losses, etc (Bhatia and Dinwoodie 2004). This study focuses in oil losses due to emulsion, flash, and mixing phenomena. Human and measurement errors, leakage, and theft are excluded. Oil loss are categorized into two categories, they are (1) individual and (2) group losses.

Yulius Deddy Hermawan

ydhermawan@upnyk.ac.id

Dedy Kristanto

dedykris.upn@gmail.com

1 Department of Chemical Engineering, Faculty of Industrial Engineering, Universitas Pembangunan Nasional "Veteran" Yogyakarta, Jl. SWK 104 (Lingkar Utara) Condongcatur, Yogyakarta 55283, Indonesia

2 Department of Petroleum Engineering, Faculty of Mineral Technology, Universitas Pembangunan Nasional "Veteran" Yogyakarta, Jl. SWK 104 (Lingkar Utara) Condongcatur, Yogyakarta 55283, Indonesia

\section{Individual loss}

Individual loss includes emulsion and evaporative losses. In order to determine emulsion loss, based sediment and water (BS\&W) of oil should be measured. The net standard volume (NSV) excludes sediment, water, and free water. So far back to year 1918, Bradley et al. (1918) have studied the crude oil losses in steel and earthen storage; they classified roughly losses as occurring from evaporation, and presence of sediment and water. Evaporative loss occurs when light components are released from oil in the storage tank. This happens when the oil temperature is lower than its bubble point. Thus, by maintaining low oil temperature minimizes evaporative loss from storage tank (Bhatia and Dinwoodie 2004).

The goals of this work are to calculate the emulsion correction factor (ECF) and flash correction factor (FCF) that occur individually in 7 shippers of Krisna field. The empiric equation of emulsion would be used to calculate ECF, while flash calculation with Antoine equation was chosen to calculate FCF. 


\section{Group loss}

Group loss occurs during mixing oils in the same storage tank. In this study, the specific characteristic which has influence on group loss is the specific gravity (SG) or API gravity. The viscosity and gas oil ratio are excluded in calculation of group loss due to mixing phenomena in the storage tank. The oil and gas fields generally produce petroleum fluid that can be classified into five categories: dry gas, wet gas, gas condensate, volatile oil, and black oil (McCain Jr. 1990a; Whitson and Brule 2000). Since the fluids in those categories have different characteristics, specifically SG or API, the properties would thus change when they are mixed together.

Typical oil mixing phenomena in the gathering station are illustrated in Fig. 1. In an activity of transporting of crude oil from shippers in the oil field to the gathering station, shippers often use the same pipeline to transport the crude oil to a storage tank. The crude oils from shippers are mixed together either in the same temporary or final storage tank. This situation comes up the problem of oil losses. As shown in Fig. 1, there is a loss discrepancy between total quantities from shippers and measurement in the storage tanks (Bhatia and Dinwoodie 2004); the total sending volume is lower than the measured volume in the mixing tank. The study of sharing oil losses is therefore very important to be done.

Several studies (Katz 1942; Erno et al. 1994; Nengkoda 2011; James 2014) have discussed about prediction of crude oil shrinkage losses. Far back to year of 1942, Katz (1942) has investigated the crude oil shrinkage phenomena and pointed that the more volatile the separator liquid phase, the more impact separator conditions and shrinkage will be. Erno et al. (1994) predicted the shrinkage equation of heavy oil/condensate blend and stated that when condensate is added to heavy oil, the blended volume is less than the sum of the condensate and oil volumes. Nengkoda (2011) has studied the role of crude oil shrinkage in heavy mix light crude in main oil pipeline and pointed that shrinkage will be very depended upon the operation pressure and temperature. In recent year 2014, James has studied shrinkage losses resulting from liquid hydrocarbon blending. James (2014) concluded that equation of API 12.3 was a valuable tool in quantifying shrinkage that occurs as a result of blending hydrocarbons of different densities. Moreover, Shanshool et al. (2011) have investigated the volumetric behavior of mixtures of different oil stock. Shanshool et al. (2011) concluded that volumetric shrinkage is resulted from blending hydrocarbon with gas oil (light oil).

The goals of this work are to calculate the shrinkage correction factor (SCF) in oil mixing phenomena and to determine the sharing oil losses using the common proportional and the new proposed stratified methods. The oil distribution of 7 shippers in Krisna field (Fig. 2) would be taken as a case study. The modified equation of API 12.3 would be used to calculate SCF in every mixing phenomenon in tank.

\section{Material and method}

\section{Flow diagram of oil distribution}

The block diagram of oil distribution and mixing phenomena in Krisna field is shown in Fig. 2. As can be seen in Fig. 2, Krisna field has 7 shippers; they are S1, S2, S3, S4, S5, S6, and S7. Shippers S1, S2, and S3 send their oil to Station-1,
Fig. 1 Typical oil mixing phenomena in gathering station

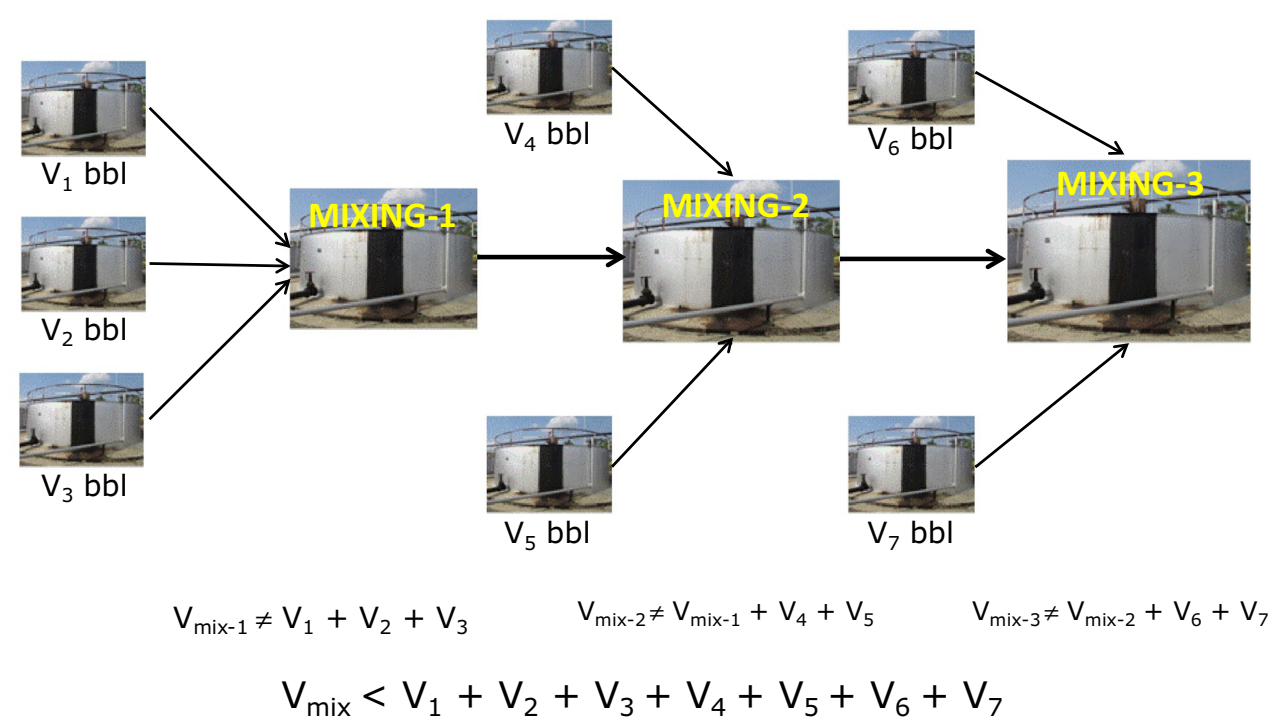




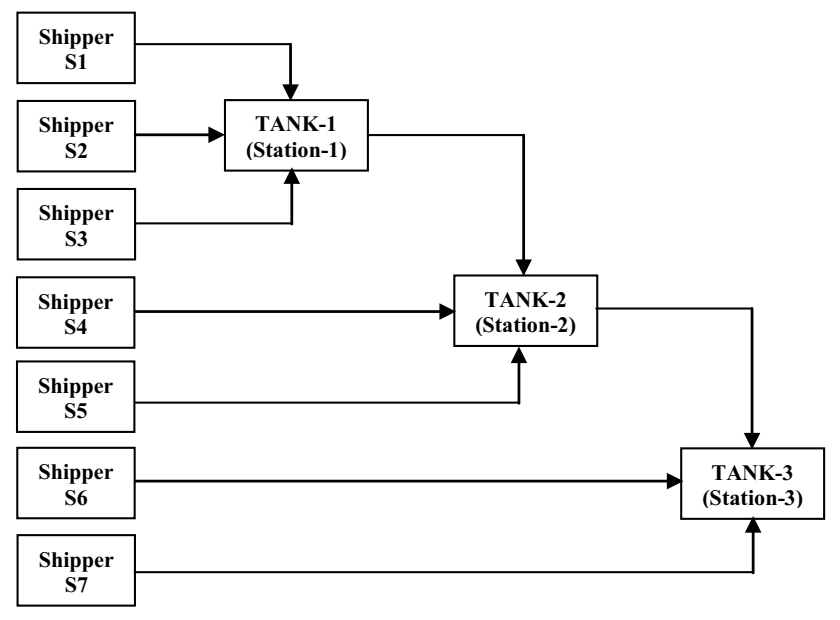

Fig. 2 Block diagram of oil distribution and mixing phenomena in Krisna field

and the oils are temporary stored in same tank of TANK-1. The mixed oil of TANK-1 is then pumped to the 2nd station and temporary stored in TANK-2 and mixed with other oils from shippers S4 and S5. Finally, the mixed oil of TANK-2 is transported to the 3rd station and stored in TANK-3 and mixed with other oils from shippers S6 and S7. As shown in Fig. 2, shippers S1, S2, and S3 have three times of mixing phenomena, shippers S4 and S5 have twice, and shippers S6 and S7 have only once.

\section{Parameter inputs}

Parameter inputs for calculating of sharing oil losses are production rate, pressure, temperature, specific gravity (SG), and based sediment water (BSW). These parameter inputs are listed in Table 1. As shown in Table 1, oils S1-S6 have the same BS\&W 0.1 vol\%, while shipper S7 produces condensate with BS\&W equals to zero. All oils are stored in the atmospheric storage tank (pressure of about $1 \mathrm{~atm}$ and temperature of about $30^{\circ} \mathrm{C}$ ). The total oil rate from all shippers as sending points is 4500 barrel oil per day (BOPD). The specific gravities (SG) of all shippers vary from 0.8001 to 0.9043 . Oil S7 is the lightest one with SG 0.8001 ; this is typically condensate. Oils S3 and S4 are typical heavy oil with SG around 0.90 .

\section{Calculation algorithm of sharing oil losses}

Calculation algorithm of sharing oil losses is shown in Fig. 3. In order to calculate the total sharing oil losses, individual loss such as emulsion and flash losses must first be calculated, and then, the group loss in mixing phenomena is determined. Sharing oil losses would be determined by two methods, they are the common proportional and the new proposed stratified methods.

\section{Calculation of emulsion loss}

Since the net oil excludes sediment, water, and free water, based sediment and water (BS\&W) of oil has to be measured. In this study, BS\&W in oils S1-S6 is taken the same $0.1 \mathrm{vol} \%$ (Table 1). While BS\&W of oil S7 equals to zero, this oil is a typical condensate. The empiric emulsion equations are used for calculating emulsion loss. The emulsion parameters $\left(a_{1}, b_{1}, a_{2}, b_{2}\right)$ for each shipper are shown in Table 2. The empiric emulsion equations and emulsion loss can be generated with following methodology:

a. Crude oil is mixed with its formation water at some levels of water volume, and the BS\&W and SG of mixed oil-water are then investigated.

b. The changes of BS\&W and SG are plotted in a curve. This first curve results linear equation:

$$
Y_{1}=a_{1} X_{1}+b_{1}
$$

Table 1 Production rate Krisna field and its properties

\begin{tabular}{|c|c|c|c|c|c|c|c|c|}
\hline \multirow[t]{2}{*}{ Shipper } & \multicolumn{3}{|l|}{ Production } & \multirow{2}{*}{$\begin{array}{l}\text { Oil Percent } \\
\text { Volume (\%) }\end{array}$} & \multicolumn{2}{|l|}{ Tank's condition } & \multicolumn{2}{|l|}{ Properties } \\
\hline & Gross (BFPD) & Oil (BOPD) & $\begin{array}{l}\text { Water } \\
\text { (BWPD) }\end{array}$ & & Pressure (atm.) & $\begin{array}{l}\text { Temperature } \\
\left({ }^{\circ} \mathrm{C}\right)\end{array}$ & $\operatorname{SG}\left(60^{\circ} / 60^{\circ}\right)$ & BS\&W \\
\hline S1 & 500 & 500 & 0 & 11.11 & 1 & 30 & 0.8881 & 0.1 \\
\hline S2 & 1200 & 1200 & 0 & 26.67 & 1 & 30 & 0.8931 & 0.1 \\
\hline S3 & 400 & 400 & 0 & 8.89 & 1 & 30 & 0.9031 & 0.1 \\
\hline S4 & 200 & 200 & 0 & 4.44 & 1 & 30 & 0.9043 & 0.1 \\
\hline S5 & 800 & 800 & 0 & 17.78 & 1 & 30 & 0.8694 & 0.1 \\
\hline S6 & 1000 & 1000 & 0 & 22.22 & 1 & 30 & 0.8912 & 0.1 \\
\hline $\mathrm{S} 7^{*)}$ & 400 & 400 & 0 & 8.89 & 1 & 30 & 0.8001 & - \\
\hline Total & 4500 & 4500 & 0 & 100.00 & & & & \\
\hline
\end{tabular}

Note $^{*)}$ : shipper $S 7$ produces condensate 


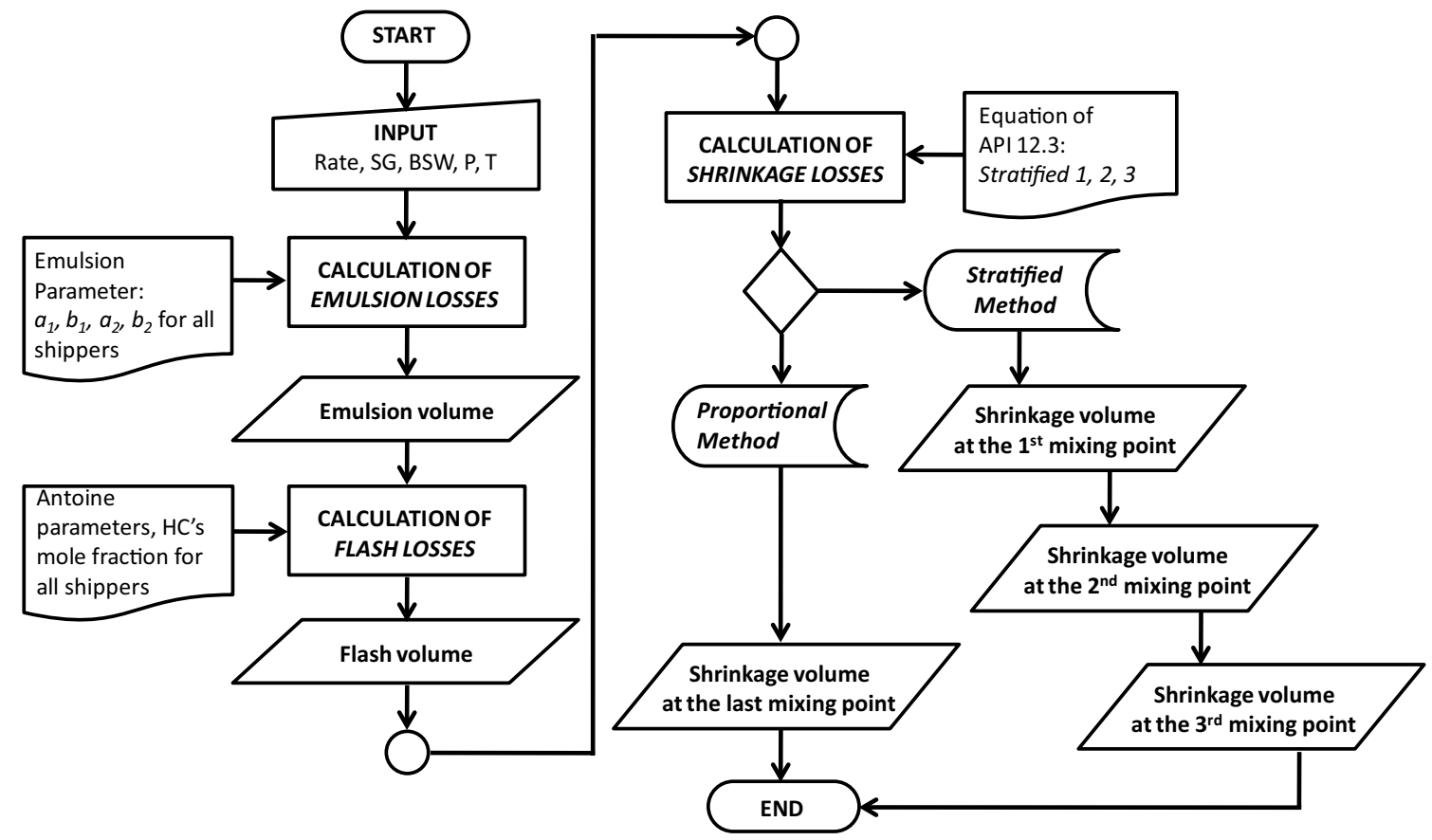

Fig. 3 Calculation algorithm of sharing oil losses

Table 2 Emulsion parameters

\begin{tabular}{|c|c|c|c|c|c|c|c|c|}
\hline \multirow[t]{2}{*}{ Shipper } & \multirow{2}{*}{$\begin{array}{l}X_{1}=\mathrm{BS} \& \mathrm{~W} \\
(\mathrm{vol} \%)\end{array}$} & \multicolumn{3}{|c|}{$Y_{1}=a_{1} X_{1}+b_{1}$} & \multicolumn{2}{|c|}{$Y_{2}=a_{2} X_{2}+b_{2}$} & \multirow{2}{*}{$\begin{array}{l}X_{2}=\left(Y_{2}-b_{2}\right) / a_{2} \\
\text { (vol\%) }\end{array}$} & \multirow{2}{*}{$\begin{array}{l}\text { ECF } \\
X_{1}-X_{2} \\
(\mathrm{vol} \%)\end{array}$} \\
\hline & & $a_{1}$ & $b_{1}$ & $Y_{1}=Y_{2}$ & $a_{2}$ & $b_{2}$ & & \\
\hline S1 & 0.1 & 0.001278 & 0.8881 & 0.888228 & 0.002892 & 0.8881 & 0.0442 & 0.0558 \\
\hline S2 & 0.1 & 0.001210 & 0.8931 & 0.893221 & 0.001564 & 0.8931 & 0.0774 & 0.0226 \\
\hline S3 & 0.1 & 0.001097 & 0.9031 & 0.903210 & 0.001146 & 0.9031 & 0.0957 & 0.0043 \\
\hline S4 & 0.1 & 0.001121 & 0.9043 & 0.904412 & 0.001615 & 0.9043 & 0.0694 & 0.0306 \\
\hline S5 & 0.1 & 0.001470 & 0.8694 & 0.869547 & 0.001800 & 0.8694 & 0.0817 & 0.0183 \\
\hline S6 & 0.1 & 0.001241 & 0.8912 & 0.891324 & 0.001524 & 0.8912 & 0.0814 & 0.0186 \\
\hline S7 & 0 & 0 & 0 & 0 & 0 & 0 & 0 & 0 \\
\hline
\end{tabular}

The constants of $a_{1}, b_{1}, a_{2}$, and $b_{2}$ are referenced from PSME of UPN "Veteran" Yogyakarta collaborated with LEMIGAS Jakarta (2017)

where $X_{1}$ is the measured BS\&W, $Y_{1}$ is the measured SG, and $a_{1}$ and $b_{1}$ are constants.

c. Then, making a curve of percentage of the addition of the volume of formation water (in vol\%) versus the calculated SG. This second curve produces linear equation:

$Y_{2}=a_{2} X_{2}+b_{2}$

where $X_{2}$ is the percentage of the addition of the volume of formation water (in vol\%), $Y_{2}$ is the calculated SG, and $a_{2}$ and $b_{2}$ are constants. The calculated SG can be found with the following equation:
$\mathrm{SG}_{\text {calculated }}=\left(1-X_{\mathrm{w}}\right) \mathrm{SG}_{\mathrm{fw}}+X_{\mathrm{w}} \mathrm{SG}_{\mathrm{w}}$

where $X_{\mathrm{w}}$ is water volume fraction in oil, $\mathrm{SG}_{\mathrm{w}}$ is specific gravity of formation water, and $\mathrm{SG}_{\mathrm{fw}}$ is specific gravity of oil free water as defined below:

$\mathrm{SG}_{\mathrm{fw}}=\frac{\mathrm{SG}_{\mathrm{o}}-X_{\mathrm{w}} \mathrm{SG}_{\mathrm{w}}}{\left(1-X_{\mathrm{w}}\right)}$

where $\mathrm{SG}_{\mathrm{o}}$ is specific gravity of oil that still contains water. 


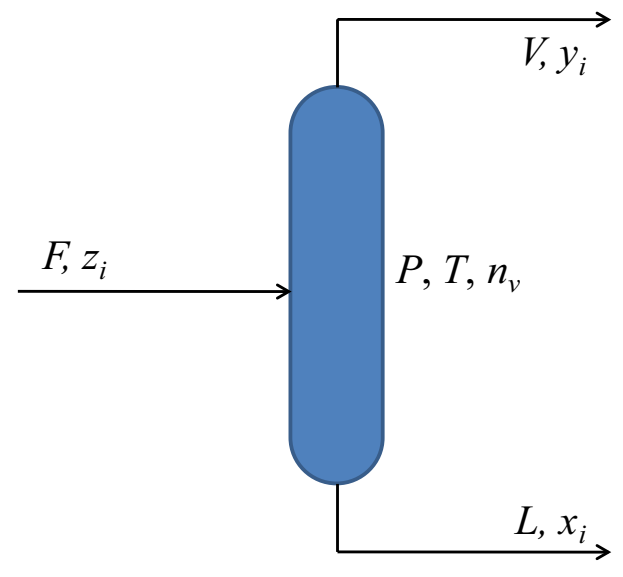

Fig. 4 Vapor-liquid equilibrium for flash calculation

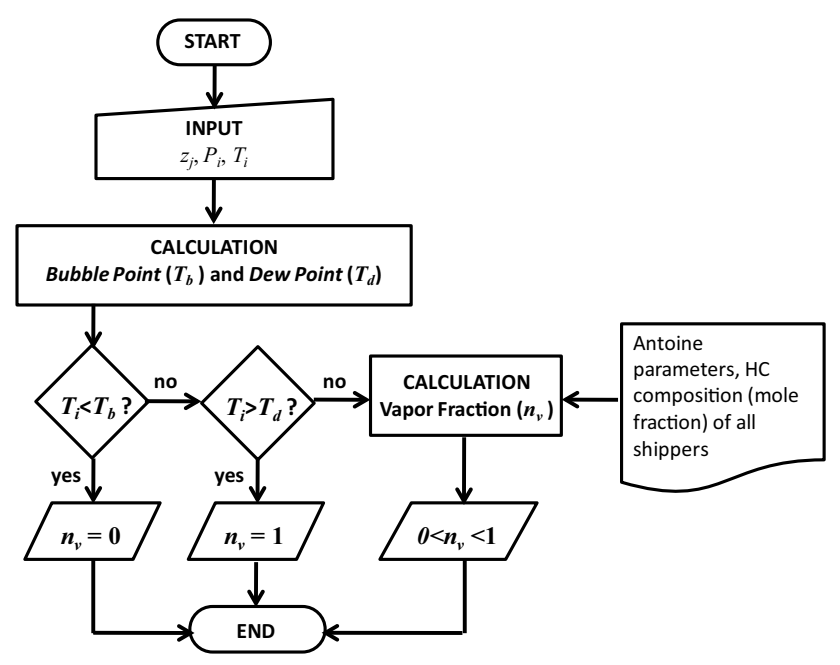

Fig. 5 Flash calculation algorithm

d. Both empiric equations are then used for calculating emulsion loss. $Y_{1}$ is found by inputting the measured BS\&W of oil as $X_{1}$ in Eq. (1). The resulted $Y_{1}$ is then substituted in Eq. (2) to calculate $X_{2}$.

e. Emulsion correction factor (ECF) in vol\% is then calculated as follows:

$\mathrm{ECF}=X_{1}-X_{2}$

\section{Calculation of evaporative loss}

Evaporative loss is calculated with flash calculation method. Mass balance diagram for flash calculation method is shown in Fig. 4. Evaporative loss depends on its operating conditions, i.e., pressure $(P)$ and temperature $(T)$. Evaporation is indicated by the value of vapor fraction $n_{v}$ (Ahmed 2007). Vapor fraction $n_{\mathrm{v}}$ ranges in between 0 and $1 . n_{\mathrm{v}}=0$ and $n_{\mathrm{v}}=1$ mean the fluid is in liquid and gas phase, respectively. If $n_{\mathrm{v}}$ is in between 0 and $1\left(0<n_{\mathrm{v}}<1\right)$, the fluid is in mixed-liquid-vapor phase; in other words, part of light component in fluid evaporates; this causes oil loss due to flash phenomena.

Flash calculation algorithm is shown in Fig. 5. Input data required in this algorithm are hydrocarbon composition $\left(z_{j}\right)$, pressure $\left(P_{i}\right)$ and temperature $\left(T_{i}\right)$ of each shipper system. The intended pressure $\left(P_{i}\right)$ is the fluid pressure in a storage tank, i.e., atmospheric pressure. Table 3 shows the hydrocarbon composition $\left(z_{j}\right)$ of each shipper. In this work, Antoine equation was chosen to calculate flash correction factor (FCF). Antoine parameters $(a, b, c, d, e, f)$ for each hydrocarbon component are listed in Table 4.

The next step is the calculations of bubble $\left(T_{\mathrm{b}}\right)$ and dew point $\left(T_{\mathrm{d}}\right)$ at the atmospheric pressure. Bubble and dew point are saturated condition at $n_{\mathrm{v}}=0$ and $n_{\mathrm{v}}=1$, respectively. Calculation procedure of $T_{\mathrm{b}}$ and $T_{\mathrm{d}}$ is written in Tables 5 and 6 , respectively. Antoine equation used in this calculation is:

$P_{\text {vap } j}=\exp \left(a_{j}+\frac{b_{j}}{\left(T+c_{j}\right)}+d_{j} \ln (T)+e_{j} T^{f_{j}}\right)$

where $P_{\text {vap } j}$ is vapor pressure of component $j$ (in $\mathrm{kPa}$ ), $T$ is temperature of system (in $\mathrm{K}$ ), and $a_{j}, b_{j}, c_{j}, d_{j}, e_{j}, f_{j}$ are Antoine parameters for each component $j$ and listed in Table 4.

After calculation $T_{\mathrm{b}}$ and $T_{\mathrm{d}}$, we calculate vapor fraction $n_{\mathrm{v}}$. Temperature $T$ and pressure $P$ of fluid (system) are the input data in calculation $n_{\mathrm{v}}$. As shown in Fig. 5, when $T$ is lower than $T_{\mathrm{b}}$ so $n_{\mathrm{v}}=0$, this indicates that the fluid is in liquid phase. When $T$ is higher than $T_{\mathrm{d}}$ so $n_{\mathrm{v}}=1$, this means that fluid is in vapor phase. When $T$ is in between $T_{\mathrm{b}}$ and $T_{\mathrm{d}}, n_{\mathrm{v}}$ is in between 0 and 1 ; this means that part of light component in fluid evaporates. Calculation procedure of $n_{\mathrm{v}}$ is shown in Table 7. Flash correction factor (FCF) is then calculated as follows:

$\mathrm{FCF}=n_{\mathrm{v}} \times 100 \%$

where FCF is in vol\%.

\section{Calculation of shrinkage loss}

The shrinkage loss is a group loss in oils mixing. The modified equation of API 12.3 is used for calculating of shrinkage loss and defined as follows:

$S_{\mathrm{h}}(\%)=a L_{\mathrm{c}}\left(100-L_{\mathrm{c}}\right)^{b}\left(\Delta^{\circ} \mathrm{API}\right)^{c}$

where $a, b$, and $c$ are constants of API 12.3 that be taken from PSME of UPN "Veteran" Yogyakarta collaborated with LEMIGAS Jakarta (2017) as listed in Table $8, L_{\mathrm{c}}$ is $\%$-light component, $\Delta^{\circ} \mathrm{API}$ is ${ }^{\circ} \mathrm{API}$ difference between ${ }^{\circ} \mathrm{API}$ 
Table 3 Hydrocarbon composition $(\%$-mol)

\begin{tabular}{|c|c|c|c|c|c|c|c|}
\hline \multirow[t]{2}{*}{ Component } & \multicolumn{7}{|l|}{ Shipper } \\
\hline & S1 & $\mathrm{S} 2$ & S3 & $\mathrm{S} 4$ & S5 & S6 & S7 \\
\hline Methane (C1) & 0.00 & 0.00 & 0.00 & 0.00 & 0.00 & 0.05 & 0.00 \\
\hline Ethane (C2) & 0.82 & 0.04 & 0.01 & 0.03 & 0.01 & 0.02 & 0.00 \\
\hline Propane (C3) & 0.98 & 0.33 & 0.03 & 0.14 & 0.27 & 0.11 & 0.00 \\
\hline Butane (C4) & 1.43 & 0.68 & 0.08 & 0.24 & 0.54 & 0.34 & 0.05 \\
\hline Pentane (C5) & 1.76 & 1.01 & 0.17 & 0.43 & 1.07 & 0.75 & 30.48 \\
\hline Hexane (C6) & 2.69 & 1.48 & 0.26 & 0.85 & 3.45 & 2.53 & 29.67 \\
\hline Heptane (C7) & 5.04 & 4.17 & 1.54 & 3.11 & 4.44 & 3.55 & 25.85 \\
\hline Octane (C8) & 8.37 & 8.15 & 3.63 & 6.88 & 8.04 & 7.25 & 12.37 \\
\hline Nonane (C9) & 6.85 & 7.56 & 4.65 & 6.66 & 7.59 & 6.77 & 1.51 \\
\hline Decane (C10) & 5.50 & 7.89 & 5.01 & 5.85 & 6.16 & 5.73 & 0.07 \\
\hline Undecane (C11) & 4.89 & 5.56 & 5.87 & 6.03 & 5.99 & 5.73 & 0.00 \\
\hline Dodecane (C12) & 3.00 & 5.49 & 5.19 & 4.88 & 4.35 & 4.39 & 0.00 \\
\hline Tridecane (C13) & 3.85 & 6.54 & 6.51 & 5.98 & 4.93 & 5.33 & 0.00 \\
\hline Tetradecane (C14) & 3.81 & 7.79 & 8.32 & 7.70 & 5.05 & 6.88 & 0.00 \\
\hline Pentadecane (C15) & 9.22 & 11.06 & 12.58 & 11.83 & 8.25 & 10.61 & 0.00 \\
\hline Heksadecane (C16) & 4.79 & 5.92 & 29.37 & 6.54 & 4.22 & 6.00 & 0.00 \\
\hline Heptadecane (C17) & 7.43 & 6.54 & 5.28 & 7.61 & 6.59 & 7.25 & 0.00 \\
\hline Oktadecane (C18) & 3.98 & 3.52 & 2.35 & 4.22 & 2.99 & 3.93 & 0.00 \\
\hline Nonadecane (C19) & 3.12 & 2.61 & 1.67 & 3.44 & 2.74 & 3.49 & 0.00 \\
\hline Eicosane (C20) & 2.62 & 1.73 & 1.05 & 2.48 & 2.25 & 2.71 & 0.00 \\
\hline Heneicosane (C21) & 2.77 & 1.48 & 0.90 & 2.19 & 2.10 & 2.32 & 0.00 \\
\hline Docosane (C22) & 2.90 & 1.32 & 0.72 & 1.95 & 2.14 & 2.14 & 0.00 \\
\hline Tricosane (C23) & 2.99 & 1.28 & 0.62 & 1.89 & 2.14 & 2.07 & 0.00 \\
\hline Tetracosane (C24) & 2.12 & 1.01 & 0.58 & 1.45 & 2.09 & 1.64 & 0.00 \\
\hline Pentacosane (C25) & 1.64 & 1.05 & 0.57 & 1.41 & 2.13 & 1.58 & 0.00 \\
\hline Hexacosane (C26) & 1.43 & 0.90 & 0.46 & 1.18 & 1.89 & 1.33 & 0.00 \\
\hline Heptacosane (C27) & 1.56 & 1.01 & 0.44 & 1.18 & 1.93 & 1.30 & 0.00 \\
\hline Octacosane (C28) & 1.25 & 1.25 & 0.49 & 1.33 & 1.88 & 1.36 & 0.00 \\
\hline Nonacosane (C29) & 1.43 & 1.55 & 0.42 & 0.98 & 1.67 & 1.22 & 0.00 \\
\hline Triacontane (C30) & 1.77 & 1.07 & 1.23 & 1.55 & 3.13 & 1.62 & 0.00 \\
\hline Total & 100.00 & 100.00 & 100.00 & 100.00 & 100.00 & 100.00 & 100.00 \\
\hline
\end{tabular}

of shipper one and other, and $S_{\mathrm{h}}$ is shrinkage volume percentage (in \%).

API gravity for each shipper is defined as the equation in McCain Jr. (1990b):

${ }^{\circ} \mathrm{API}_{i}=\frac{141.5}{\mathrm{SG}_{i}}-131.5$

where ${ }^{\circ} \mathrm{API}_{i}$ is API gravity of shipper $i$ and $\mathrm{SG}_{i}$ is specific gravity $\left(60^{\circ} / 60^{\circ}\right)$ of shipper $i$.

Proportional method Proportional method is the common method used in petroleum industries for sharing oil losses. In this method, the total received volume is measured at the last station. This measured volume is the net corrected volume $\left(V_{\mathrm{nc}}\right)$ which is directly taken from the last storage tank in the last station (TANK-3 in Fig. 2). The total shrinkage volume ( $\left.V_{\text {sh-prop }}\right)$ is the difference volume between the total volume sent from all shippers and the net corrected volume:

$V_{\text {sh-prop }}=\sum_{i=1}^{n} V_{i}-V_{\text {nc (TANK-3) }}$

where $V_{i}$ is net standard volume of shipper $i$ and $V_{\text {nc (TANK-3) }}$ is the net corrected volume in TANK-3. The proportional shrinkage volume for each shipper $\left(\xi_{\text {prop }_{i}}\right)$ can be calculated as follows:

$\xi_{\text {prop }_{i}}=\frac{x_{i}\left(1 / \mathrm{SG}_{i}\right)}{\sum_{i=1}^{n} x_{i}\left(1 / \mathrm{SG}_{i}\right)} V_{\text {sh-prop }}$

where $x_{i}$ is volume fraction of shipper $i$ as defined below: 
Table 4 Antoine parameters for hydrocarbon: $T$ in $\mathrm{K} ; P$ in $\mathrm{kPa}$

\begin{tabular}{|c|c|c|c|c|c|c|}
\hline \multirow{3}{*}{$\begin{array}{l}\text { Component } \\
\text { Methane (C1) }\end{array}$} & \multicolumn{6}{|c|}{$P_{\text {vap }}=\exp \left(a+\frac{b}{(T+c)}+d \ln (T)+e T^{f}\right)$} \\
\hline & \multicolumn{3}{|c|}{$a \quad b$} & $d$ & e & $f$ \\
\hline & 31.35 & -1307.52 & 0.00 & -3.26 & 0.00 & 2.00 \\
\hline Ethane (C2) & 44.01 & -2568.82 & 0.00 & -4.98 & 0.00 & 2.00 \\
\hline Propane (C3) & 52.38 & -3490.55 & 0.00 & -6.11 & 0.00 & 2.00 \\
\hline Butane (C4) & 66.95 & -4604.09 & 0.00 & -8.25 & 0.00 & 2.00 \\
\hline Pentane (C5) & 63.33 & -5117.78 & 0.00 & -7.48 & 0.00 & 2.00 \\
\hline Hexane (C6) & 70.43 & -6055.60 & 0.00 & -8.38 & 0.00 & 2.00 \\
\hline Heptane (C7) & 78.33 & -6947.00 & 0.00 & -9.45 & 0.00 & 2.00 \\
\hline Octane (C8) & 87.00 & -7890.60 & 0.00 & -10.63 & 0.00 & 2.00 \\
\hline Nonane (C9) & 111.98 & -9558.50 & 0.00 & -14.27 & 0.00 & 2.00 \\
\hline Decane (C10) & 123.14 & $-10,635.20$ & 0.00 & -15.81 & 0.00 & 2.00 \\
\hline Undecane (C11) & 121.16 & $-11,079.20$ & 0.00 & -15.38 & 0.00 & 2.00 \\
\hline Dodecane (C12) & 125.19 & $-11,737.00$ & 0.00 & -15.87 & 0.00 & 2.00 \\
\hline Tridecane (C13) & 14.12 & -3892.90 & -98.93 & 0.00 & 0.00 & 2.00 \\
\hline Tetradecane (C14) & 143.58 & $-13,893.70$ & 0.00 & -18.30 & 0.00 & 2.00 \\
\hline Pentadecane (C15) & 152.64 & $-14,762.20$ & 0.00 & -19.55 & 0.00 & 2.00 \\
\hline Heksadecane (C16) & 225.02 & $-18,736.50$ & 0.00 & -30.23 & 0.00 & 2.00 \\
\hline Heptadecane (C17) & 14.14 & -4294.53 & -124.00 & 0.00 & 0.00 & 2.00 \\
\hline Oktadecane (C18) & 14.11 & -4361.79 & -129.90 & 0.00 & 0.00 & 2.00 \\
\hline Nonadecane (C19) & 14.14 & -4450.43 & -135.50 & 0.00 & 0.00 & 2.00 \\
\hline Eicosane (C20) & 196.75 & $-19,441.00$ & 0.00 & -25.53 & 0.00 & 2.00 \\
\hline Heneicosane (C21) & 133.88 & $-17,129.00$ & 0.00 & -15.87 & 0.00 & 6.00 \\
\hline Docosane (C22) & 147.40 & $-18,406.00$ & 0.00 & -17.69 & 0.00 & 6.00 \\
\hline Tricosane (C23) & 212.92 & $-21,841.00$ & 0.00 & -27.53 & 0.00 & 2.00 \\
\hline Tetracosane (C24) & 204.51 & $-21,711.00$ & 0.00 & -26.26 & 0.00 & 2.00 \\
\hline Pentacosane (C25) & 152.24 & $-19,976.00$ & 0.00 & -18.16 & 0.00 & 6.00 \\
\hline Hexacosane (C26) & 148.73 & $-20,116.00$ & 0.00 & -17.62 & 0.00 & 6.00 \\
\hline Heptacosane (C27) & 148.85 & $-20,612.00$ & 0.00 & -17.55 & 0.00 & 6.00 \\
\hline Octacosane (C28) & 285.21 & $-28,200.00$ & 0.00 & -37.54 & 0.00 & 2.00 \\
\hline Nonacosane (C29) & 201.65 & $-24,971.00$ & 0.00 & -24.75 & 0.00 & 6.00 \\
\hline Triacontane (C30) & 188.81 & $-22,404.00$ & 0.00 & -23.36 & 0.00 & 6.00 \\
\hline
\end{tabular}

Table 5 Calculation procedure of bubble point $\left(T_{\mathrm{b}}\right)$

\begin{tabular}{lll}
\hline Nos. & Procedure & Formula \\
\hline 1 & $\begin{array}{c}\text { Input data: vapor fraction } n_{\mathrm{v}}=0 \text {, pressure } P \text {, and HC composition } z_{i} \text { of all } \\
\text { shippers }(i) \\
\text { Calculation of vapor pressure of component } j \text { with guessed temperature } T_{i}\end{array}$ & $n_{v i}=0, P_{i}, z_{i}$ \\
2 & Calculation of equilibrium ratio of component $K_{j}$ & $\exp \left(a_{j}+\frac{b_{j}}{\left(T_{i}+c_{j}\right)}+d_{j} \ln \left(T_{i}\right)+e_{j} T_{i}^{f_{j}}\right)$ \\
3 & Calculation of objective function $f\left(n_{\mathrm{v} i}\right)$, where $n_{\mathrm{v}}=0$ & $K_{j}=\frac{P_{\mathrm{v}_{j}}}{P_{i}}$ \\
4 & Repeat procedure number $2-4$ with other value of $T_{i}$ until $f\left(n_{\mathrm{v} i}\right)=0$ & $f\left(n_{\mathrm{v}_{i}}\right)=\sum_{j=1}^{n} y_{j}-\sum_{j=1}^{n} x_{j}=\sum_{j=1}^{n} \frac{z_{j}\left(K_{j}-1\right)}{n_{\mathrm{v}} K_{j}-n_{\mathrm{v}}+1}=0$ \\
\hline
\end{tabular}

$i=$ shipper $; j=$ component $\mathrm{HC}$ 
Table 6 Calculation procedure of dew point $\left(T_{\mathrm{d}}\right)$

\begin{tabular}{lll}
\hline Nos. & Procedure & Formula \\
\hline 1 & $\begin{array}{l}\text { Input data: vapor fraction } n_{\mathrm{v}}=1 \text {, pressure } P \text {, and HC composition } z_{i} \text { of all } \\
\text { Shippers }(i)\end{array}$ & $n_{\mathrm{v} i}=1, P_{i}, z_{i}$ \\
2 & Calculation of vapor pressure of component $j$ with guessed temperature $T_{i}$ & $P_{\mathrm{v} j}=\exp \left(a_{j}+\frac{b_{j}}{\left(T_{i}+c_{j}\right)}+d_{j} \ln \left(T_{i}\right)+e_{j} T_{i}^{f_{j}}\right)$ \\
3 & Calculation of equilibrium ratio of component $K_{j}$ & $K_{j}=\frac{P_{\mathrm{v}_{j}}}{P_{i}}$ \\
4 & Calculation of objective function $f\left(n_{\mathrm{v} i}\right)$, where $n_{\mathrm{v}}=1$ & $f\left(n_{\mathrm{v}_{i}}\right)=\sum_{j=1}^{n} y_{j}-\sum_{j=1}^{n} x_{j}=\sum_{j=1}^{n} \frac{z_{j}\left(K_{j}-1\right)}{n_{\mathrm{v}} K_{j}-n_{\mathrm{v}}+1}=0$ \\
\hline
\end{tabular}

$i=$ shipper $; j=$ component $\mathrm{HC}$

Table 7 Calculation procedure of vapor fraction $\left(n_{\mathrm{v}}\right)$

\begin{tabular}{lll}
\hline Nos. & Procedure & Formula \\
\hline 1 & $\begin{array}{c}\text { Input data: temperature } T, \text { pressure } P \text {, and HC com- } \\
\text { position } z_{i} \text { of all shippers }(i)\end{array}$ & $T_{i}, P_{i}, z_{i}$ \\
2 & $\begin{array}{l}\text { Calculation of vapor pressure of component } j \\
3\end{array}$ & $P_{\mathrm{v} j}=\exp \left(a_{j}+\frac{b_{j}}{\left(T_{i}+c_{j}\right)}+d_{j} \ln \left(T_{i}\right)+e_{j} T_{i}^{f_{j}}\right)$ \\
4 & $\begin{array}{c}\text { Calculation of equilibrium ratio of component } K_{j} \\
\text { Calculation of objective function } f\left(n_{\mathrm{v} i}\right) \text { with guessed }\end{array}$ & $K_{j}=\frac{P_{\mathrm{v}_{j}}}{P_{i}}$ \\
& $\begin{array}{l}\text { vapor fraction } n_{\mathrm{v}} \\
\text { Repeat procedure number 2-4 with other value of } n_{\mathrm{v}} \\
\text { until } f\left(n_{\mathrm{v} i}\right)=0\end{array}$ & Same with no. 4 \\
&
\end{tabular}

Table 8 Parameters $a, b, c$ in API 12.3 equations

\begin{tabular}{llll}
\hline Group & \multicolumn{3}{l}{$S_{\mathrm{h}}(\%)=a \times L_{\mathrm{c}} \times\left(100-L_{\mathrm{c}}\right)^{b} \times(\Delta \mathrm{API})^{c}$} \\
\cline { 2 - 4 } & \multicolumn{2}{l}{ Constant } & $c$ \\
\cline { 2 - 4 } & $a$ & 0.819 & 0.98 \\
TANK-1 & $4.86 \times 10^{-5}$ & 0.819 & 0.60 \\
TANK-2 & $4.86 \times 10^{-5}$ & 0.819 & 0.24 \\
\hline
\end{tabular}

The constants of $a, b, c$ are referenced from PSME of UPN "Veteran" Yogyakarta collaborated with LEMIGAS Jakarta (2017)

$x_{i}=\frac{V_{i}}{\sum_{i=1}^{n} V_{i}}$

The proportional shrinkage correction factor $\left(\mathrm{SCF}_{\text {prop }_{i}}\right.$ in vol\%) for each shipper can then be calculated as follows:

$\mathrm{SCF}_{\text {prop }_{i}}=\frac{\xi_{\text {prop }_{i}}}{V_{i}} \times 100 \%$

Stratified method In new proposed stratified method, the net corrected volume is calculated stratify from tank to tank as shown in Tables 9 and 10. The shrinkage volume is calculated for each mixing phenomena in TANK-1, TANK-2, and
TANK-3. The shrinkage volume for shippers S1, S2, and S3 in TANK-1 can be calculated with the following equation:

$\xi_{\mathrm{st}-\mathrm{I} i}=\frac{x_{i}\left(1 / \mathrm{SG}_{i}\right)}{\sum_{i=1}^{n} x_{i}\left(1 / \mathrm{SG}_{i}\right)} V_{\text {shg-I }}$

where $\xi_{\mathrm{st}-I i}$ is shrinkage volume for shipper $i$ (S1, S2, and S3) in TANK-1 and $V_{\text {shg- }}$ is the group shrinkage volume in TANK-1. The shrinkage volume for shippers S4, S5, and TANK-1 (mix S1-S2-S3) in TANK-2 can be calculated with the following equation:

$\xi_{\mathrm{st}-\mathrm{II} i}=\frac{x_{i}\left(1 / \mathrm{SG}_{i}\right)}{\sum_{i=1}^{n} x_{i}\left(1 / \mathrm{SG}_{i}\right)} V_{\text {shg-II }}$

where $\xi_{\mathrm{st}-\mathrm{II} i}$ is shrinkage volume for shipper $i$ (S4, S5, and mix S1-S2-S3) in TANK-2 and $V_{\text {shg-II }}$ is the group shrinkage volume in TANK-2. Finally, the shrinkage volume for shippers S6, S7, and TANK-2 (mix S1-S2-S3-S4-S5) in TANK-3 can be calculated as follows:

$\xi_{\mathrm{st}-\mathrm{III} i}=\frac{x_{i}\left(1 / \mathrm{SG}_{i}\right)}{\sum_{i=1}^{n} x_{i}\left(1 / \mathrm{SG}_{i}\right)} V_{\text {shg-III }}$ 
Table 9 Calculation procedure of shrinkage volume in tanks

\begin{tabular}{|c|c|c|}
\hline Nos. & Procedure & Formula \\
\hline 1 & $\begin{array}{l}\text { Input data: net volume }\left(V_{\text {net- } i}\right) \text {, specific gravity }\left(\mathrm{SG}_{i}\right) \text { for } \\
\text { each shipper }(i)\end{array}$ & $V_{\text {net }-i}, \mathrm{SG}_{i}$ \\
\hline 2 & Calculation of ${ }^{\circ} \mathrm{API}_{i}$ for each shipper $(i)$ & ${ }^{\circ} \mathrm{API} i=\frac{141.5}{S G_{i}}-131.5$ \\
\hline \multirow[t]{7}{*}{3} & $\begin{array}{l}\text { a. Calculation of the } 1 \text { st total volume }\left(V_{\text {tot } 1}\right) \\
\text { b. Calculation of the } 1 \text { st } \% \text {-light component }\left(\operatorname{Lc}_{1}\right)\end{array}$ & $\begin{array}{l}V_{\text {tot1 }}=V_{\text {net }}(1)+V_{\text {net }}(2) \\
\text { if } \mathrm{SG}(1)<\mathrm{SG}(2): \mathrm{Lc}_{1}=\frac{V_{\text {net }}(1)}{V_{\text {tot1 }}} 100 \\
\text { if } \mathrm{SG}(1)>\mathrm{SG}(2): \mathrm{Lc}_{1}=\frac{V_{\text {net }}(2)}{V_{\text {tot1 }}} 100\end{array}$ \\
\hline & c. Calculation of the 1 st $\Delta^{\circ} \mathrm{API}\left(\Delta^{\circ} \mathrm{API}_{1}\right)$ & $\Delta^{\circ} \mathrm{API}_{1}=\operatorname{abs}\left({ }^{\circ} \mathrm{API}(1)-{ }^{\circ} \mathrm{API}(2)\right)$ \\
\hline & d. Calculation of the 1st \%-shrinkage $\left(S_{h 1}\right)$ & $S_{\mathrm{h} 1}(\%)=a \mathrm{Lc}_{1}\left(100-\mathrm{Lc}_{1}\right)^{b}\left(\Delta^{\circ} \mathrm{API}_{1}\right)^{c}$ \\
\hline & e. Calculation of the 1st shrinkage volume $\left(V_{\mathrm{sh} 1}\right)$ & $V_{\mathrm{sh} 1}=\frac{S_{\mathrm{h} 1}}{100} V_{\mathrm{tot} 1}$ \\
\hline & f. Calculation of the 1 st mixed volume $\left(V_{\operatorname{mix} 1}\right)$ & $V_{\operatorname{mix} 1}=V_{\text {tot } 1}-V_{\text {sh1 }}$ \\
\hline & g. Calculation of the 1st mixed SG $\left(\mathrm{SG}_{\text {mix } 1}\right)$ & $\mathrm{SG}_{\text {mix } 1}=\frac{V_{\text {net }}(1) \mathrm{SG}(1)+V_{\text {net }}(2) \mathrm{SG}(2)}{V_{\text {mix } 1}}$ \\
\hline & h. Calculation of the 1 st mixed ${ }^{\circ} \mathrm{API}\left({ }^{\circ} \mathrm{API} \mathrm{I}_{\operatorname{mix} 1}\right)$ & ${ }^{\circ} \mathrm{API} \mathrm{m}_{\operatorname{mix} 1}=\frac{141.5}{\mathrm{SG}_{\mathrm{mix} 1}}-131.5$ \\
\hline \multirow[t]{8}{*}{4} & a. Calculation of the 2 nd total volume $\left(V_{\text {tot2 }}\right)$ & $V_{\text {tot2 }}=V_{\text {mix } 1}+V_{\text {net }}(3)$ \\
\hline & b. Calculation of the 2 nd $\%$-light component $\left(\mathrm{Lc}_{2}\right)$ & $\begin{array}{l}\text { if } \mathrm{SG}_{\mathrm{mix} 1}<\mathrm{SG}(3): \mathrm{Lc}_{2}=\frac{V_{\text {mix } 1}}{V_{\text {tot2 }}} 100 \\
\text { if } \mathrm{SG}_{\mathrm{mix} 1}>\mathrm{SG}(3): \mathrm{Lc}_{2}=\frac{V_{\text {net }}(3)}{V_{\mathrm{tot} 2}} 100\end{array}$ \\
\hline & c. Calculation of the 2 nd $\Delta^{\circ} \mathrm{API}\left(\Delta^{\circ} \mathrm{API}_{2}\right)$ & $\Delta^{\circ} \mathrm{API}_{2}=\operatorname{abs}\left({ }^{\circ} \mathrm{API}_{\operatorname{mix} 1}-{ }^{\circ} \mathrm{API}(3)\right)$ \\
\hline & d. Calculation of the 2 nd $\%$-shrinkage $\left(S_{\mathrm{h} 2}\right)$ & $S_{\mathrm{h} 2}(\%)=a \mathrm{Lc}_{2}\left(100-\mathrm{Lc}_{2}\right)^{b}\left(\Delta^{\mathrm{o}} \mathrm{API}_{2}\right)^{c}$ \\
\hline & e. Calculation of the 2 nd shrinkage volume $\left(V_{\mathrm{sh} 2}\right)$ & $V_{\mathrm{sh} 2}=\frac{S_{\mathrm{h} 2}}{100} V_{\mathrm{tot} 2}$ \\
\hline & f. Calculation of the 2 nd mixed volume $\left(V_{\operatorname{mix} 2}\right)$ & $V_{\mathrm{mix} 2}=V_{\mathrm{tot} 2}-V_{\mathrm{sh} 2}$ \\
\hline & g. Calculation of the 2nd mixed SG $\left(\mathrm{SG}_{\mathrm{mix} 2}\right)$ & $\mathrm{SG}_{\text {mix } 2}=\frac{V_{\text {mix } 2} \mathrm{SG}_{\text {mix } 2}+V_{\text {net }}(3) \mathrm{SG}(3)}{V_{\operatorname{mix} 2}}$ \\
\hline & h. Calculation of the 2 nd mixed ${ }^{\circ} \mathrm{API}\left({ }^{\circ} \mathrm{API} \mathrm{mix}_{2}\right)$ & ${ }^{\circ} \mathrm{API} \mathrm{I}_{\operatorname{mix} 2}=\frac{141.5}{\mathrm{SG}_{\operatorname{mix} 2}}-131.5$ \\
\hline 5 & Calculation of net corrected volume in tank $\left(V_{\mathrm{nc}}\right)$ & $V_{\mathrm{nc}}=V_{\mathrm{mix} 2}$ \\
\hline 6 & Calculation of group shrinkage losses in tank $\left(V_{\text {shg }}\right)$ & $V_{\text {shg }}=V_{\text {sh } 1}+V_{\text {sh2 }}$ \\
\hline
\end{tabular}

This table shows the stratification of oil mix in tank listed in Table 10
Table 10 Notes of Table 9: stratification of oil mix in tank

\begin{tabular}{llll}
\hline (i) & \multicolumn{2}{l}{ Shippers' oil mix in tank } \\
\cline { 2 - 4 } & TANK-1 & TANK-2 & TANK-3 \\
\hline (1) & Shipper S1 & TANK-1 & TANK-2 \\
(2) & Shipper S2 & Shipper S4 & Shipper S6 \\
(3) & Shipper S3 & Shipper S5 & Shipper S7 \\
\hline
\end{tabular}

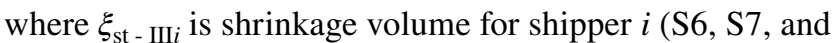
mix S1-S2-S3-S4-S5) in TANK-3 and $V_{\text {shg-III }}$ is the group shrinkage volume in TANK-3.

The total stratified shrinkage volume $\left(\xi_{\text {st - toti }}\right)$ for shippers $\mathrm{S} 1, \mathrm{~S} 2$, and $\mathrm{S} 3$ is the summation of its shrinkage volume in TANK-1, TANK-2, and TANK-3, that for shippers S4 and S5 is the summation of its shrinkage volume in TANK-2 and TANK-3, while that for shippers S6 and S7 is only its shrinkage volume in the last tank of TANK-3.

$\xi_{\mathrm{st}-\mathrm{tot} i}=\xi_{\mathrm{st}-\mathrm{I} i}+\xi_{\mathrm{st}-\mathrm{II} i}+\xi_{\mathrm{st}-\mathrm{III} i}$

where for S4 and S5 $\xi_{\mathrm{st}-\mathrm{I} i}=0$, and for S6 and S7 $\xi_{\mathrm{st}-\mathrm{I} i}=\xi_{\mathrm{st}-\mathrm{II} i}=0$.
The stratified shrinkage correction factor $\left(\mathrm{SCF}_{\mathrm{St}_{i}}\right.$ in vol\%) for each shipper can then be calculated as follows:

$\mathrm{SCF}_{\mathrm{st}_{i}}=\frac{\xi_{\mathrm{st}^{-\mathrm{tot}_{i}}}}{V_{i}} \times 100 \%$

\section{Result and discussion}

\section{Individual loss results}

Individual loss includes emulsion and evaporative losses and must be determined to get the net standard volume (NSV) of all petroleum liquids. The NSV excluding sediment, water (and free water), and vapor is then used for calculating group loss in mixing phenomena. The total individual losses (TIL) including emulsion and evaporative loss is listed in Table 11. TIL of shipper S1 is the biggest one, i.e., 0.28 barrel. While TIL of shipper S7 equals to zero, oil S7 is a typical condensate which has no emulsion. The total TIL and NSV resulted from the individual loss calculation are 0.96 and 4499.04 barrel, respectively. 
Table 11 Individual losses

\begin{tabular}{lcllllllr}
\hline Shipper & $\begin{array}{l}\text { Gross } \\
\text { (barrel) }\end{array}$ & $\begin{array}{l}\text { BS\&W } \\
(\text { vol\% })\end{array}$ & $\begin{array}{l}\text { ECF } \\
(\text { vol\% })\end{array}$ & $\begin{array}{l}\text { EV } \\
(\text { barrel })\end{array}$ & $\begin{array}{l}\text { FCF } \\
(\text { vol\% })\end{array}$ & $\begin{array}{l}\text { VV } \\
\text { (barrel) }\end{array}$ & $\begin{array}{l}\text { TIL } \\
\text { (barrel) }\end{array}$ & $\begin{array}{l}\text { NSV } \\
\text { (barrel) }\end{array}$ \\
\hline S1 & 500 & 0.1 & 0.0558 & 0.2790 & 0 & 0 & 0.28 & 499.72 \\
S2 & 1200 & 0.1 & 0.0226 & 0.2716 & 0 & 0 & 0.27 & 1199.73 \\
S3 & 400 & 0.1 & 0.0043 & 0.0171 & 0 & 0 & 0.02 & 399.98 \\
S4 & 200 & 0.1 & 0.0306 & 0.0612 & 0 & 0 & 0.06 & 199.94 \\
S5 & 800 & 0.1 & 0.0183 & 0.1467 & 0 & 0 & 0.15 & 799.85 \\
S6 & 1000 & 0.1 & 0.0186 & 0.1857 & 0 & 0 & 0.19 & 999.81 \\
S7 & 400 & 0 & 0.0000 & 0.0000 & 0 & 0 & 0.00 & 400.00 \\
& & & & & Total & & 0.96 & 4499.04 \\
\hline
\end{tabular}

$B S \& W$ based sediment \& water (vol\%), ECF emulsion correction factor (vol\%), $E V$ emulsion volume (barrel), $F C F$ flash correction factor (vol\%), $V V$ vapor volume (barrel), TIL total individual losses (barrel), NSV net standard volume (barrel)

Fig. 6 Sensitivity BS\&W against ECF

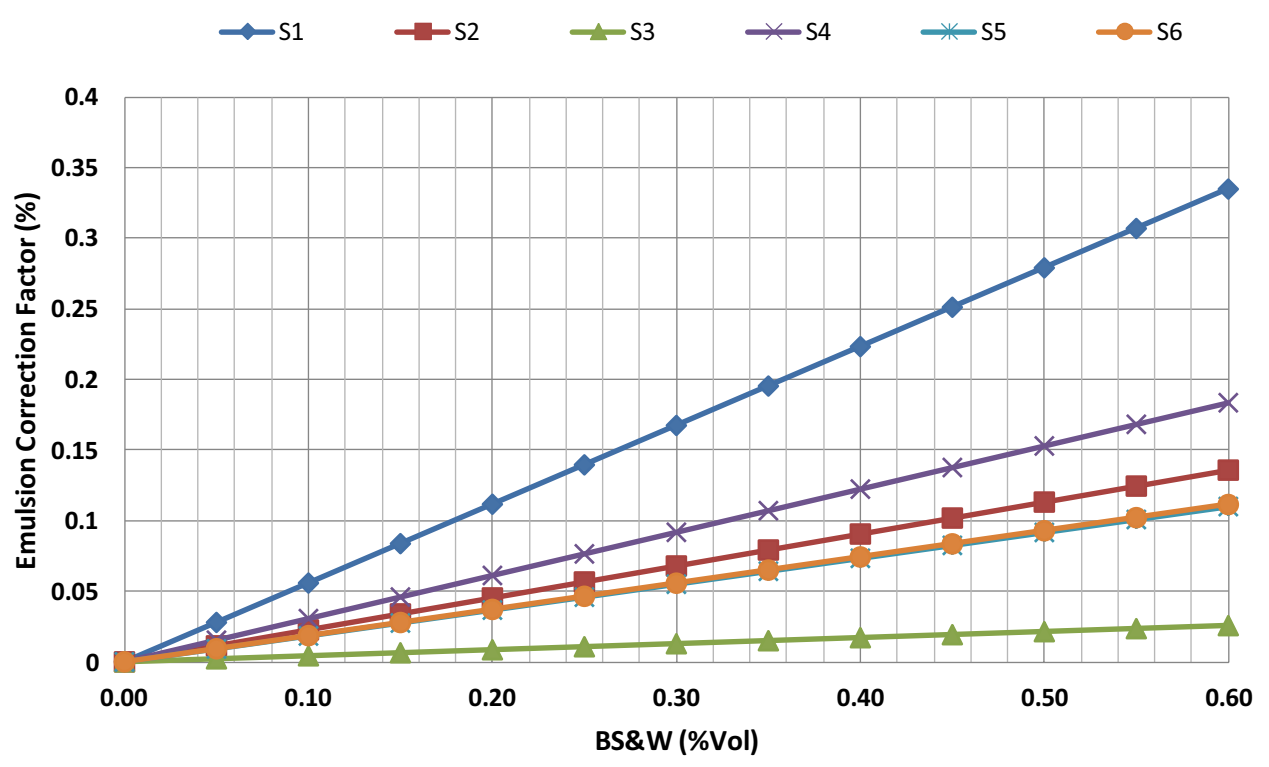

Table 12 Normal bubble and dew points of crude oils

\begin{tabular}{|c|c|c|}
\hline Shippers & Bubble point $\left(T_{\mathrm{b}}\right),\left({ }^{\circ} \mathrm{C}\right)$ & $\begin{array}{l}\text { Dew point } \\
\left(T_{\mathrm{d}}\right),\left({ }^{\circ} \mathrm{C}\right)\end{array}$ \\
\hline S1 & 57.91 & 341.60 \\
\hline S2 & 131.25 & 330.60 \\
\hline S3 & 197.66 & 314.85 \\
\hline S4 & 158.48 & 335.28 \\
\hline S5 & 134.29 & 348.45 \\
\hline S6 & 72.98 & 338.07 \\
\hline S7 & 61.73 & 92.00 \\
\hline
\end{tabular}

\section{Emulsion loss}

By inputting $\mathrm{BS} \& \mathrm{~W}=0.1 \%$ in the equation system (Eq. 1-5), emulsion correction factors (ECFs) for all shippers are found and listed in Table 11. The biggest and smallest ECFs are given by shipper S1 and S3, respectively. The sensitivity BS\&W against EFC is shown in Fig. 6. Shipper $\mathrm{S} 1$ is the most sensitive compared with others; its ECF increases significantly by increasing its BS\&W. While shipper $\mathrm{S} 3$ is not sensitive to a change in $\mathrm{BS} \& \mathrm{~W}$, its ECF raises slowly by increasing its BS\&W.

\section{Evaporative loss}

In atmospheric pressure condition (about $1 \mathrm{~atm}$ ), evaporation can happen when the fluid temperature is higher than its bubble point. The normal bubble $\left(T_{\mathrm{b}}\right)$ and dew $\left(T_{\mathrm{d}}\right)$ points resulted from flash calculation are listed in Table 12. Oil S7 is a typical condensate; it has the shortest span between $T_{\mathrm{b}}$ and $T_{\mathrm{d}}$. Correlation of vapor pressure and bubble point for all shippers is shown in Fig. 7. Since the oil temperatures in all tanks are lower than its bubble point (Fig. 7), it is understandable that all shippers have no evaporative loss. Flash correction factors (FCFs) of all shippers equal to zero. During operation in the oil gathering station, by maintaining oil 
Fig. 7 Correlation of vapor pressure and bubble temperature

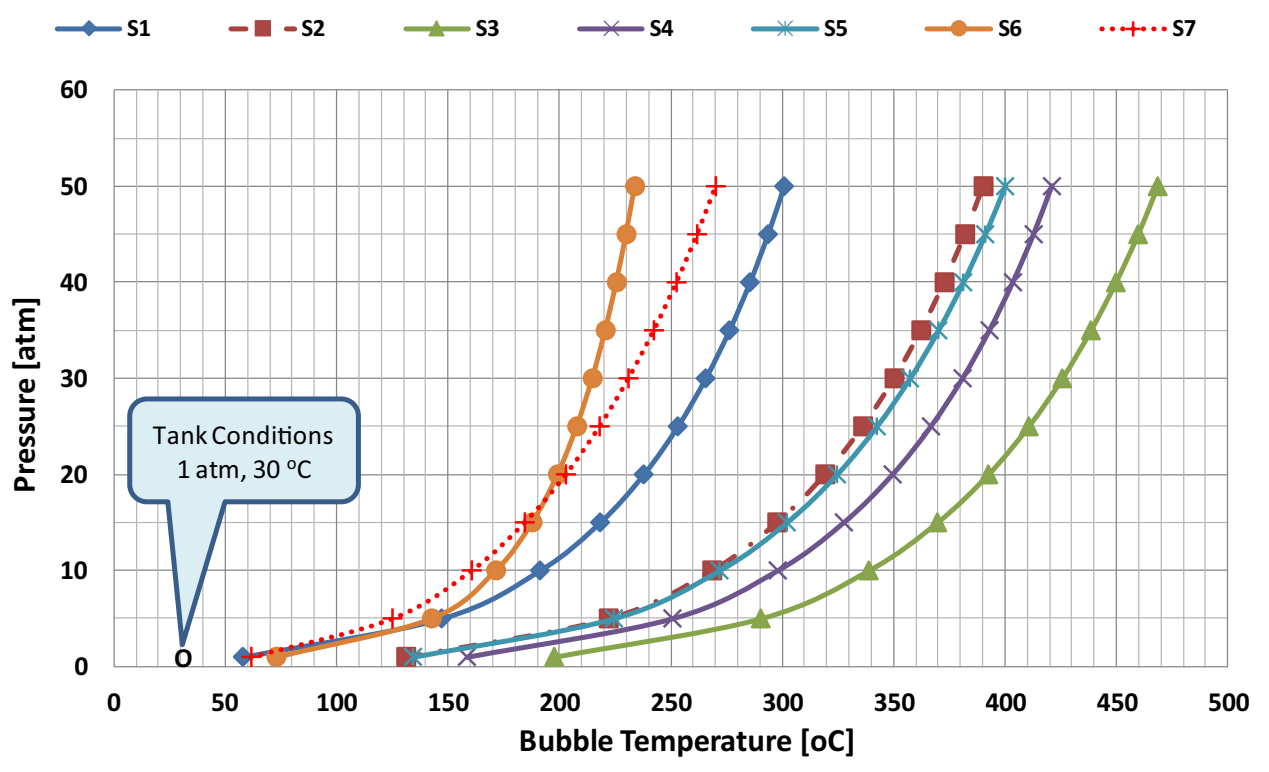

\begin{tabular}{lclllll}
\hline Shipper & NSV (barrel) & SG & $x$ & $x$ SG & \multicolumn{2}{l}{ Shrinkage loss } \\
\cline { 5 - 7 } & & & & & Volume (barrel) & SCF (\%) \\
\hline S1 & 499.72 & 0.8881 & 0.1111 & 0.1251 & 1.00 & 0.20 \\
S2 & 1199.73 & 0.8931 & 0.2667 & 0.2986 & 2.38 & 0.20 \\
S3 & 399.98 & 0.9031 & 0.0889 & 0.0984 & 0.78 & 0.20 \\
S4 & 199.94 & 0.9043 & 0.0444 & 0.0491 & 0.39 & 0.20 \\
S5 & 799.85 & 0.8694 & 0.1778 & 0.2045 & 1.63 & 0.20 \\
S6 & 999.81 & 0.8912 & 0.2222 & 0.2494 & 1.99 & 0.20 \\
S7 & 400.00 & 0.8001 & 0.0889 & 0.1111 & 0.89 & 0.22 \\
Total & 4499.04 & & & 1.1362 & 9.06 &
\end{tabular}

Net corrected volume in the last tank (barrel) $=4489.98$

Total shrinkage loss $($ barrel $)=9.06$

$N S V$ net standard volume (barrel), SCF shrinkage correction factor (vol\%), $S G$ specific gravity, $x$ volume fraction

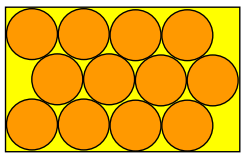

heavy oil (I)
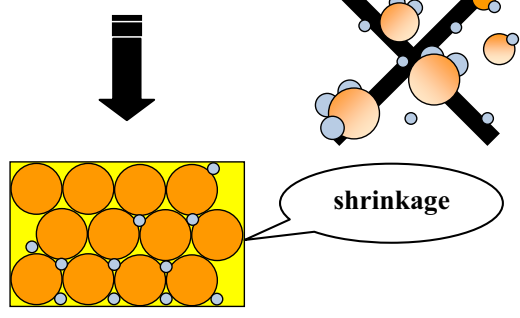

mixed volume $<$ I + II

Fig. 8 Illustration of shrinkage volume from mixing of heavy and light oils temperature lower than its bubble point can eliminate evaporative loss from storage tank (Bhatia and Dinwoodie 2004).

\section{Shrinkage loss}

\section{Proportional shrinkage loss}

Sharing oil losses resulted by the common proportional method are listed in Table 13. As can be seen from Table 13, the total shrinkage loss is 9.06 barrel and the shrinkage correction factors (SCFs) of all shippers are almost the same $\pm 0.20 \%$. However, SCF of shipper S7 is the largest one $(0.22 \%)$ since its oil is classified as condensate. Condensate is typically light oil or gas oil that has low density and small molecular size, while heavy oil has big molecular size. When condensate mixes heavy oil, hence geometrically there 


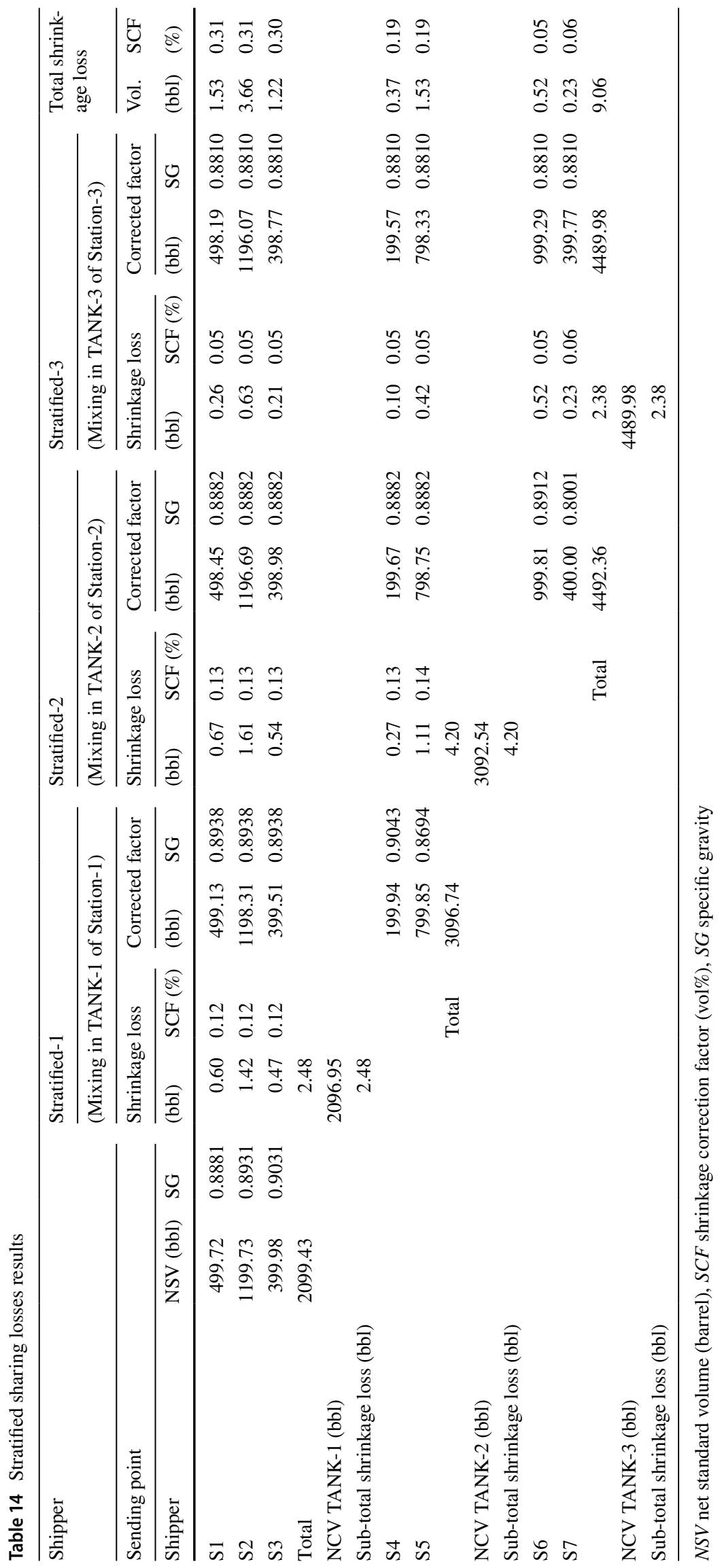


Table 15 Comparison between proportional and stratified results

\begin{tabular}{|c|c|c|c|c|c|c|c|}
\hline \multirow[t]{3}{*}{ Shipper } & \multicolumn{2}{|l|}{ Sending point } & \multirow{3}{*}{$\begin{array}{l}\text { Mixing } \\
\text { quantity }\end{array}$} & \multicolumn{4}{|c|}{ Shrinkage losses } \\
\hline & \multirow[t]{2}{*}{ NSV (barrel) } & \multirow[t]{2}{*}{ SG } & & \multicolumn{2}{|c|}{ Proportional } & \multicolumn{2}{|c|}{ Stratified } \\
\hline & & & & (bbl) & $\mathrm{SCF}(\%)$ & (bbl) & $\mathrm{SCF}(\%)$ \\
\hline S1 & 499.72 & 0.8881 & 3 & 1.00 & 0.20 & 1.53 & 0.31 \\
\hline S2 & 1199.73 & 0.8931 & 3 & 2.38 & 0.20 & 3.66 & 0.31 \\
\hline S3 & 399.98 & 0.9031 & 3 & 0.78 & 0.20 & 1.22 & 0.30 \\
\hline S4 & 199.94 & 0.9043 & 2 & 0.39 & 0.20 & 0.37 & 0.19 \\
\hline S5 & 799.85 & 0.8694 & 2 & 1.63 & 0.20 & 1.53 & 0.19 \\
\hline S6 & 999.81 & 0.8912 & 1 & 1.99 & 0.20 & 0.52 & 0.05 \\
\hline S7 & 400.00 & 0.8001 & 1 & 0.89 & 0.22 & 0.23 & 0.06 \\
\hline Total & 4499.04 & & & 9.06 & & 9.06 & \\
\hline \multicolumn{8}{|c|}{ Net corrected volume in last tank $=4489.98$ barrel } \\
\hline
\end{tabular}

$N S V$ net standard volume (barrel), $S C F$ shrinkage correction factor (vol\%), $S G$ specific gravity will be shrinkage as illustrated in Fig. 8; and this agrees with those in Erno et al. (1994), James (2014), and Shanshool et al. (2011).

\section{Stratified shrinkage loss}

Table 14 shows sharing oil losses resulted by the new proposed stratified method. In this method, shrinkage volume of each shipper is calculated for every mixing in the tank. As can be seen from Table 14, the sub-total oil losses in every tank are $2.48,4.20$, and 2.38 barrels, respectively. The total oil loss in the stratified method is the same as in the proportional method, i.e., 9.06 barrels. The SCF of each shipper in every tank is almost the same; they are $0.12 \%, 0.13 \%$, and $0.05 \%$ in TANK-1, TANK-2, and TANK-3, respectively. The total SCFs of shippers S1, S2, and S3 are larger than those in shippers S4 and S5 (0.31\% vs. 0.19\%), and those in shippers $\mathrm{S} 4$ and S5 are larger than those in shippers S6 and S7 $(0.19 \%$ vs. $0.05 \%$ ). This is understandable that more often oil mixes with others; its volume will be more decreased.

\section{Comparison of proportional and stratified results}

Comparison between proportional and stratified results is listed in Table 15. The total NSV is 4499.04 barrels, and total shrinkage volume is 9.06 barrel. Therefore, the net corrected volume (NCV) in the last tank is 4490.94 barrel. The proportional method gives almost the same of SCF, $\pm 0.20 \%$, while SCF resulted by stratified method varies from 0.05 to $0.31 \%$ depending on its mixing quantity.

The common proportional method is considered unfair since shippers S6 and S7 bear those losses of the upstream shippers (S1-S5). More often oil mixes with others, for examples oils of shippers S1, S2, and S3 pass through three times of mixing phenomena, more volume shrinkage will be.
Thus, the stratified method appropriates for determining of sharing oil losses in the multi-mixing phenomena.

\section{Conclusion}

Study on oil losses due to emulsion, flash (evaporation), and mixing phenomena in a Krisna field has been done. The oil loss is classified into two types, i.e., individual loss including emulsion and evaporative loss, and group loss which occurs in mixing phenomena. The individual loss must be determined to get the net standard volume (NSV). The NSV excluding sediment, water (and free water), and gas is then used for calculating group loss.

The emulsion correction factor (ECF) has been calculated for each shipper based on its BS\&W. Since oil of shipper S7 is a condensate, it does not produce emulsion. According to our analysis, shipper $\mathrm{S} 1$ is the most sensitive to a change in BS\&W; its ECF increases significantly by increasing its BS\&W. While shipper S3 is not sensitive to a change in $\mathrm{BS} \& \mathrm{~W}$; its ECF raises slowly by increasing its BS\&W.

Based on flash calculation results, all oils which are stored in tanks are the stable liquids. Since the oils' temperatures in tanks are lower than its bubble points at the normal condition (atmospheric), it is clear that all shippers have no evaporative loss. Flash correction factor $(\mathrm{FCF})$ of all shippers equal to zero. Evaporative loss could be prevented by maintaining oil temperature lower than its bubble point.

In this work, the common proportional and new proposed stratified methods have been used to determine the sharing oil losses for 7 shippers in Krisna field. According to our analysis, the common proportional method gave almost the same of shrinkage correction factor (SCF) for all shippers. However, shippers that more often mix with others, e.g., shippers S1, S2, and S3 have three times of mixing

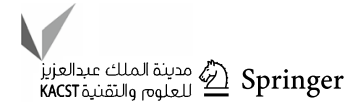


phenomena; their shrinkage volume was larger than others. For that reason, the new proposed stratified method is strongly recommended to determine sharing oil losses since it gives a fair result.

Open Access This article is distributed under the terms of the Creative Commons Attribution 4.0 International License (http://creativeco mmons.org/licenses/by/4.0/), which permits unrestricted use, distribution, and reproduction in any medium, provided you give appropriate credit to the original author(s) and the source, provide a link to the Creative Commons license, and indicate if changes were made.

\section{References}

Ahmed T (2007) Equations of state and PVT analysis: applications for improved reservoir modeling. Gulf Publishing Company, Houston

Bhatia R, Dinwoodie J (2004) Daily oil losses in shipping crude oil: measuring crude oil loss rates in daily North Sea shipping operations. Energy Policy 32(2004):811-822. https://doi.org/10.1016/ S0301-4215(03)00003-X

Bradley OU, Muskogee EM, Okla (1918) Losses of crude oil in steel and earthen storage. In: Colorado meeting, pp 624-628

Erno BP, Chriest J, Given R (1994) Equation predicts shrinkage of heavy oil/condensate blend. Oil Gas J. https://www.ogj.com/artic les/print/volume-92/issue-49/in-this-issue/production/equationpredicts-shrinkage-of-heavy-oil-condensate-blend.html. Accessed 18 Apr 2018

James H (2014) Shrinkage loses resulting from liquid hydrocarbon blending. iMEC Cooperation. https://nfogm.no/wp-content/uploa
ds/2014/04/Shrinkage-Loses-Resulting-from-Liquid-Hydrocarbo n-Blending-by-James.pdf. Accessed 18 Apr 2018

Katz DL (1942) Prediction of the shrinkage of crude oil, MISCELLANEOUS. In: Presented at twenty-third annual meeting, Chicago, III, Nov 1942, pp 137-147

McCain WD Jr (1990a) Component of naturally occurring petroleum fluids, in the properties of petroleum fluids, 2nd edn. PennWell Books, PennWell Publishing Company, Tulsa, pp 1-45

McCain WD Jr (1990b) Properties of black oils-definition, in the properties of petroleum fluids, 2nd edn. PennWell Books, PennWell Publishing Company, Tulsa, pp 224-225

Nengkoda A (2011) The role of crude oil shrinkage in heavy mix light crude in main oil pipeline: case study Oman. SPE 148925 , Dec 2011, pp 1-6. http://www.nioclibrary.ir/Reports/8898.pdf. Accessed 18 Apr 2018

PSME (Study Center of Mineral and Energy) of UPN "Veteran" Yogyakarta collaborated with LEMIGAS Jakarta (2017). Oil losses study of oil distribution in "P" field (in Indonesian)

Shanshool J, Habobi N, Kareem S (2011) Volumetric behavior of mixtures of different oil stock. Pet Coal J 53 (3):223-228. http://www. vurup.sk/wp-content/uploads/dlm_uploads/2017/07/pc_3_2011_ habobi_118_0.pdf. Accessed 18 Apr 2018

Whitson CH, Brule MR (2000) Volumetric and phase behavior of oil and gas systems. In: Doherty HL (ed) Phase behavior. Memorial fund of AIME. Society of Petroleum Engineers Inc. Richardson, pp 1-13

Publisher's Note Springer Nature remains neutral with regard to jurisdictional claims in published maps and institutional affiliations. 